\title{
Early goal-directed resuscitation of patients with septic shock: current evidence and future directions
}

\author{
Ravi G. Gupta ${ }^{1 *}$, Sarah M. Hartigan², Markos G. Kashiouris ${ }^{1}$, Curtis N. Sessler ${ }^{1}$ and Gonzalo M. L. Bearman ${ }^{3}$
}

\begin{abstract}
Severe sepsis and septic shock are among the leading causes of mortality in the intensive care unit. Over a decade ago, early goal-directed therapy (EGDT) emerged as a novel approach for reducing sepsis mortality and was incorporated into guidelines published by the international Surviving Sepsis Campaign. In addition to requiring early detection of sepsis and prompt initiation of antibiotics, the EGDT protocol requires invasive patient monitoring to guide resuscitation with intravenous fluids, vasopressors, red cell transfusions, and inotropes. The effect of these measures on patient outcomes, however, remains controversial. Recently, three large randomized trials were undertaken to re-examine the effect of EGDT on morbidity and mortality: the ProCESS trial in the United States, the ARISE trial in Australia and New Zealand, and the ProMISe trial in England. These trials showed that EGDT did not significantly decrease mortality in patients with septic shock compared with usual care. In particular, whereas early administration of antibiotics appeared to increase survival, tailoring resuscitation to static measurements of central venous pressure and central venous oxygen saturation did not confer survival benefit to most patients. In the following review, we examine these findings as well as other evidence from recent randomized trials of goaldirected resuscitation. We also discuss future areas of research and emerging paradigms in sepsis trials.
\end{abstract}

\section{Introduction}

The Italian philosopher Niccolo Machiavelli wrote in his classic treatise The Prince, 'a hectic fever, in its beginning, is difficult to recognize but easy to cure; in the course of time, it becomes easy to recognize but difficult to cure'. Five centuries later, his insightful observation remains largely true for patients with sepsis. With over 750,000 cases documented in the United States each year, severe sepsis and septic shock are among the leading causes of mortality in critically ill patients and cost the health-care system nearly $\$ 17$ billion annually $[1,2]$. The incidence of sepsis has increased over the last two decades, a trend likely driven by aging patient populations, the emergence of drug-resistant pathogens, and increased use of immunosuppressive drugs $[3,4]$. Mortality rates remain high and range from $10 \%$ to $50 \%$ despite advances in critical care medicine $[5,6]$.

\footnotetext{
* Correspondence: guptar4@vcu.edu

'Division of Pulmonary Disease and Critical Care Medicine, Department of Internal Medicine, Virginia Commonwealth University School of Medicine, P.O. Box 980050, Richmond, VA 23298, USA

Full list of author information is available at the end of the article
}

Although our understanding of the pathophysiology of sepsis has significantly improved since the 1970s, current treatment options continue to focus primarily on antibiotics and supportive care. An influential study by Rivers and colleagues [7] in 2001 introduced a novel treatment protocol called early goal-directed therapy (EGDT), which was shown to increase survival among patients with septic shock at a single institution. The EGDT protocol comprised a set of tasks to be completed within the first 6 hours of presentation, including the placement of a central venous catheter to monitor hemodynamic variables during fluid resuscitation. Resuscitation was titrated to specific targets of central venous pressure (CVP), mean arterial pressure (MAP), and central venous oxygen saturation $\left(\mathrm{ScvO}_{2}\right)$. In 2004, this approach was adopted by the international Surviving Sepsis Campaign (SSC) and incorporated into sepsis care 'bundles' that continue to be used in the intensive care unit (ICU) [8].

Although there is broad consensus that early diagnosis of sepsis and prompt initiation of antibiotics improve 
patient survival, methods of initial resuscitation and hemodynamic monitoring remain controversial $[9,10]$. Previous studies have shown that CVP is a poor marker of fluid responsiveness in critically ill patients [11]. Furthermore, although central venous catheters may offer valuable information during resuscitation, they can result in complications such as pneumothorax and infection in over $15 \%$ of patients [12]. The debate was recently revisited with the publication of randomized controlled trials of EGDT that failed to replicate positive findings of the original study by Rivers and colleagues. This new evidence may have significant implications for future iterations of SSC guidelines and clinical practice. In the following review, we discuss current evidence for early goal-directed resuscitation of patients with septic shock as well as novel areas of research.

\section{Pathophysiology of septic shock}

The American College of Chest Physicians and Society of Critical Care Medicine have established clinical criteria for systemic inflammatory response syndrome, sepsis, severe sepsis, and septic shock (Table 1) [13]. The pathogenic sequence of sepsis begins with the growth of microorganisms at a site of infection, most commonly in the lungs, abdomen, or urinary tract. The infection either spreads into the bloodstream and results in positive blood cultures or grows locally and induces factors that stimulate the release of endogenous mediators of systemic inflammation [14]. These mediators can have a significant effect on the vasculature and heart, ultimately

Table 1 Diagnostic criteria for sepsis

\begin{tabular}{|c|c|}
\hline Diagnosis & Clinical criteria \\
\hline \multirow{5}{*}{$\begin{array}{l}\text { Systemic inflammatory } \\
\text { response syndrome (SIRS) }\end{array}$} & Two or more of the following: \\
\hline & $\begin{array}{l}\text { - Fever (core temperature of more than } \\
38^{\circ} \mathrm{C} \text { ) or hypothermia (core temperature } \\
\text { of less than } 36^{\circ} \mathrm{C} \text { ) }\end{array}$ \\
\hline & $\begin{array}{l}\text { - Heart rate of more than } 90 \text { beats per } \\
\text { minute }\end{array}$ \\
\hline & $\begin{array}{l}\text { - Respiratory rate of more than } 20 \text { breaths } \\
\text { per minute or partial pressure of carbon } \\
\text { dioxide in arterial blood }\left(\mathrm{PaCO}_{2}\right) \text { of less } \\
\text { than } 32 \mathrm{~mm} \mathrm{Hg}\end{array}$ \\
\hline & $\begin{array}{l}\text { - Leukocytosis (white-cell count of more } \\
\text { than } 12,000 \text { cells/ } \mu \text { l) or leukopenia } \\
\text { (white-cell count of less than } 4,000 \\
\text { cells/ } \mu \text { l) or more than } 10 \% \text { immature } \\
\text { forms (bands) }\end{array}$ \\
\hline Sepsis & $\begin{array}{l}\text { Confirmed infection and at least two } \\
\text { SIRS criteria }\end{array}$ \\
\hline Severe sepsis & $\begin{array}{l}\text { Sepsis and organ dysfunction as evidenced } \\
\text { by arterial hypoxemia, lactic acidosis, } \\
\text { oliguria, altered mental status, and so on }\end{array}$ \\
\hline Septic shock & $\begin{array}{l}\text { Sepsis and hypotension refractory to } \\
\text { fluid resuscitation }\end{array}$ \\
\hline
\end{tabular}

manifesting as hypotension, systemic hypoperfusion, and progressive failure of multiple organs.

Hypotension in sepsis occurs due to peripheral vasodilation and redistribution of intravascular fluid. Vasodilation is thought to result from the release of vasoactive mediators produced by vascular endothelial cells, including prostacyclin and nitric oxide $[15,16]$. Inflammatory cytokines disrupt endothelial cell junctions, causing increased capillary permeability and fluid shift into the extravascular space. The overall effect of these changes is tissue hypoperfusion and organ dysfunction, although cardiac output is usually preserved or increased. Occasionally, sepsis can depress the myocardium, causing refractory distributive and cardiogenic shock [17].

A central goal in the treatment of septic shock, therefore, is the maintenance of adequate tissue perfusion with hemodynamic support, which includes intravenous fluid resuscitation and administration of vasopressors, inotropes, and packed red blood cells. This general approach is predicated upon the theory that organ dysfunction results from intravascular volume depletion, peripheral vasodilation, and myocardial depression. A growing body of evidence suggests that impairment of the microvascular network may also have key pathogenic roles (Fig. 1) [18-20]. However, few studies have examined the physiologic effects of intravenous fluid resuscitation beyond 30 to 60 minutes post-administration, and the effects of fluid bolus therapy on microcirculation remain poorly understood [21].

\section{Initial management}

The SSC advocates early recognition of septic shock and initiation of empiric antibiotics within the first hour of treatment. The SSC also recommends obtaining at least two blood cultures prior to initiation of antibiotics. This recommendation is based on data from a retrospective study by Kumar and colleagues [22], which showed that each hour delay in the administration of appropriate antibiotics was associated with a $7.6 \%$ increase in mortality. Other observational studies have provided similar evidence of the survival benefit conferred by appropriate antimicrobial therapy [23]. Despite a lack of evidence from prospective randomized trials, few experts would argue against the use of these measures to identify and control the source of infection in sepsis [24].

Guidelines from the SSC published in 2013 also recommend goal-directed resuscitation during the first 6 hours of septic shock (Fig. 2). In this approach, treatment with intravenous fluids is titrated to specific endpoints, including CVP of 8 to $12 \mathrm{~mm} \mathrm{Hg}$ and $\mathrm{ScvO}_{2}$ of at least $70 \%$. The SSC recommends placing a central venous catheter to monitor these variables and using a minimum of $30 \mathrm{ml}$ per $\mathrm{kg}$ of fluids during initial resuscitation. Other goals of resuscitation include the use of vasopressor therapy to 


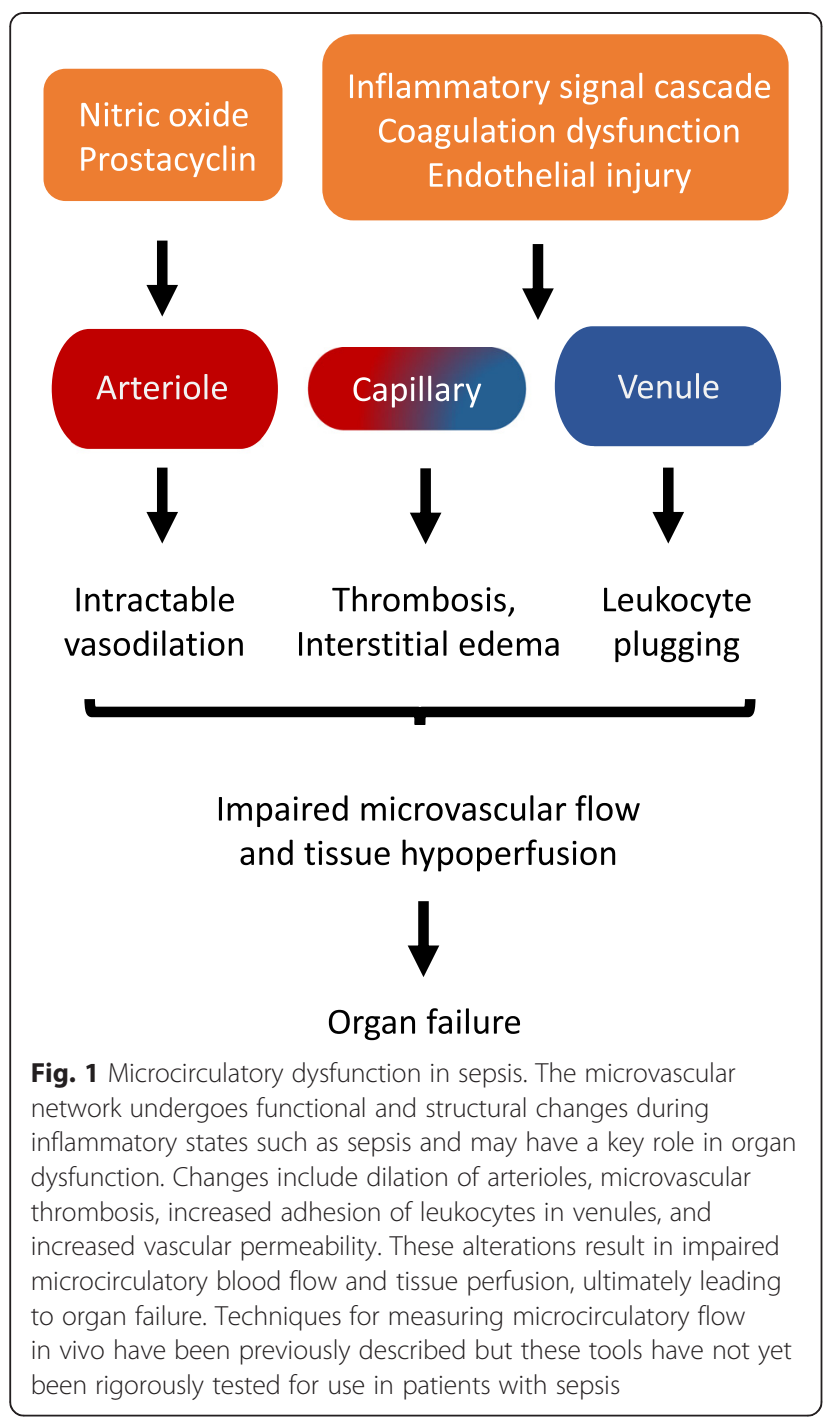

achieve an MAP of at least $65 \mathrm{~mm} \mathrm{Hg}$ in patients with refractory hypotension as well as inotropic therapy in patients with low cardiac output. In patients with $\mathrm{ScvO}_{2}$ persistently below $70 \%$ during the first 6 hours, the SSC advocates the use of packed red blood cell transfusions with a target hematocrit of at least $30 \%$.

These recommendations are based primarily on evidence from the 2001 trial by Rivers and colleagues, which showed that EGDT reduced the absolute risk of in-hospital mortality by $16 \%$. Dozens of reports since the trial by Rivers and colleagues have shown improved patient outcomes with EGDT [25-46]. However, the majority of these were non-randomized studies and thus prone to selection bias and confounding variables [47]. Furthermore, the bundled approach of EGDT precludes identification of which elements of the protocol are primarily responsible for reductions in mortality reported in clinical trials.

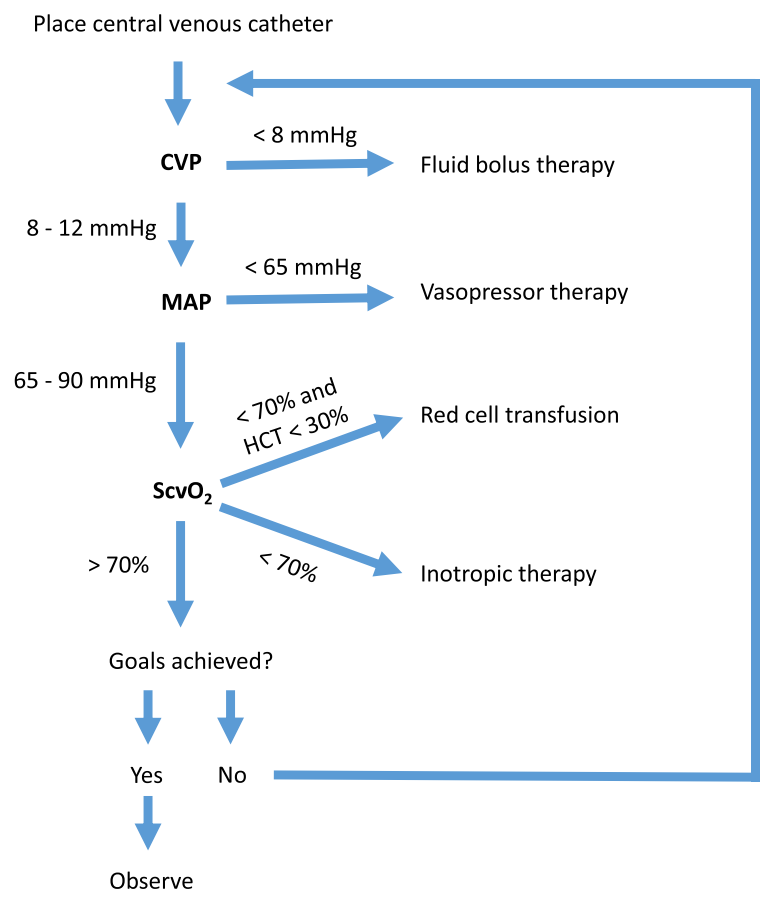

Fig. 2 Early goal-directed therapy. During the first 6 hours of septic shock, the early goal-directed therapy protocol requires the placement of a central venous catheter with an oximetric port for continuous monitoring of central venous pressure (CVP) and central venous oxygen saturation $\left(\mathrm{SCVO}_{2}\right)$. Resuscitation with intravenous fluids, vasopressors, and packed red blood cells is titrated to specific end-points, including CVP of 8 to $12 \mathrm{~mm} \mathrm{Hg}$, mean arterial pressure (MAP) of at least $65 \mathrm{~mm} \mathrm{Hg}$, and $\mathrm{ScvO}_{2}$ of at least $70 \%$ Inotropic therapy is recommended in patients with low cardiac output despite adequate volume and MAP. Recent controlled clinical trials have challenged the efficacy of this approach for reducing mortality among patients with septic shock. HCT hematocrit

\section{Goals of early goal-directed therapy: central venous pressure and central venous oxygen saturation}

Recently, three large randomized controlled trials enrolling a total of 4,183 patients were completed to reexamine the effect of early goal-directed resuscitation on outcomes in patients with septic shock: the Protocolized Care for Early Septic Shock (ProCESS) trial in the United States, the Australasian Resuscitation in Sepsis Evaluation (ARISE) trial, and the Protocolised Management of Sepsis (ProMISe) trial in England (Table 2). Each trial used inclusion criteria similar to the original study by Rivers and colleagues and was powered to detect a $6 \%$ to $8 \%$ absolute mortality reduction [48].

The ProCESS trial enrolled patients drawn from 31 academic hospitals in the United States who were diagnosed with septic shock [49]. Patients were randomly assigned to one of three treatment groups: EGDT with continuous monitoring of CVP and $\mathrm{ScvO}_{2}$, protocolized 
Table 2 Randomized trials of early goal-directed therapy for patients with septic shock

\begin{tabular}{|c|c|c|c|c|c|c|c|c|c|c|}
\hline \multirow[t]{2}{*}{ Trial } & \multirow[t]{2}{*}{ Study setting } & \multirow[t]{2}{*}{ Sample size } & \multicolumn{3}{|c|}{ Baseline characteristics of patients receiving EGDT } & \multicolumn{4}{|c|}{ EGDT in the first 6 hours } & \multirow{2}{*}{$\begin{array}{l}\text { Mortality } \\
\text { EGDT vs. usual care, \% }\end{array}$} \\
\hline & & & APACHE II score & Lactate, $\mathrm{mmol} / \mathrm{l}$ & Source of sepsis & Total fluids, I & $\begin{array}{l}\text { Vasopressor } \\
\text { therapy, \% }\end{array}$ & $\begin{array}{l}\text { Red cell } \\
\text { transfusion, \% }\end{array}$ & Inotropic therapy, \% & \\
\hline Rivers et al. [7] & Single center in USA & 263 & $21.4 \pm 6.9$ & $7.7 \pm 4.7$ & $\begin{array}{l}38.5 \% \text { lungs, } 25.6 \% \\
\text { urinary, } 35.9 \% \text { other }\end{array}$ & $4.9 \pm 2.9$ & 27.4 & 64.1 & 13.7 & 44.3 vs. $56.9^{\mathrm{a}}(P=0.03)$ \\
\hline ProCESS [49] & 31 centers in USA & 1,341 & $20.8 \pm 8.1$ & $4.8 \pm 3.1$ & $\begin{array}{l}31.9 \% \text { lungs, } 22.8 \% \\
\text { urinary, } 45.3 \% \text { other }\end{array}$ & $2.8 \pm 1.9$ & 54.9 & 14.4 & 8.0 & 21.0 vs. $18.9^{\mathrm{a}}(P=0.83)$ \\
\hline ARISE [50] & $\begin{array}{l}51 \text { centers in Australia } \\
\text { and New Zealand }\end{array}$ & 1,591 & $15.4 \pm 6.5$ & $6.7 \pm 3.3$ & $\begin{array}{l}36.5 \% \text { lungs, } 18.7 \% \\
\text { urinary, } 44.8 \% \text { other }\end{array}$ & $2.5 \pm 1.2$ & 66.6 & 13.6 & 15.4 & 18.6 vs. $18.8^{\mathrm{b}}(P=0.90)$ \\
\hline ProMISe [52] & 56 centers in England & 1,251 & $18.7 \pm 7.1$ & $7.0 \pm 3.5$ & $\begin{array}{l}36.5 \% \text { lungs, } 17.3 \\
\text { urinary, } 46.2 \% \text { other }\end{array}$ & $2.2 \pm 1.4$ & 53.3 & 8.8 & 18.1 & 29.5 vs. $29.2^{b}(P=0.90)$ \\
\hline \multicolumn{11}{|c|}{$\begin{array}{l}\text { The Protocolized Care for Early Septic Shock (ProCESS), Australasian Resuscitation in Sepsis Evaluation (ARISE), and Protocolised Management of Sepsis (ProMISe) trials failed to replicate positive findings of the original } \\
\text { trial by Rivers and colleagues [7]. The study by Rivers and colleagues was conducted at a single emergency department in a low-income community of Detroit, Michigan. It had a high control group mortality rate, } \\
\text { which likely reflects health problems unique to an impoverished patient population as well as delays in treatment. Still, a subgroup analysis in the ARISE trial showed that early goal-directed therapy (EGDT) did not } \\
\text { improve mortality in patients with increased disease severity (Acute Physiology and Chronic Health Evaluation II (APACHE II) score }>25, \mathrm{n}=69 \text { ). Control group mortality rates were markedly lower in the ProCESS, ARISE, } \\
\text { and ProMISe trials, which may reflect broad shifts in clinical practice over the last decade toward earlier initiation of antibiotics and vasopressor therapy as well as conservative thresholds for blood transfusion. Indeed, } \\
\text { the ARISE trial reported a median time of } 70 \text { minutes between initial presentation and administration of antibiotics in the EGDT group versus } 67 \text { minutes in usual care } \\
\text { a Mortality at } 60 \text { days } \\
\text { b Mortality at } 90 \text { days }\end{array}$} \\
\hline
\end{tabular}


standard therapy that did not require continuous monitoring, and usual care. In the usual care group, patient care was directed by clinicians acting without a standardized protocol. Patients in the three groups received significantly different volumes of intravenous fluids within the first 6 hours and those in the EGDT group were most likely to receive vasopressors, inotropes, and red cell transfusions. Despite these differences, no significant change in 60-day mortality or need for organ support was identified.

The ARISE trial in Australia and New Zealand offered concordant evidence [50]. Management of sepsis in Australasia does not typically incorporate goal-directed resuscitation protocols advocated by the SSC. Apart from antimicrobial therapy and source control, standard care during the first 6 hours comprises less aggressive fluid infusions and earlier use of vasopressors than what is recommended by SSC guidelines [51]. The ARISE study enrolled patients drawn from 51 urban and rural hospitals who were diagnosed with septic shock. Patients were randomly assigned to receive either EGDT or usual care. Measurement of CVP and $\mathrm{ScvO}_{2}$ using central lines was strictly limited to EGDT and was not permitted in the usual care group. Patients in the EGDT group received significantly more fluids and were more likely to receive vasopressors, inotropes, and red cell transfusions compared with the usual care group. However, no significant difference in 90-day mortality, need for organ support, or length of hospital stay was identified.

The ProMISe trial showed findings consistent with evidence from ProCESS and ARISE and also reported on cost-effectiveness of the EGDT protocol [52]. Patients with septic shock were drawn from 56 hospitals in England and were randomly assigned to receive either a 6-hour sepsis care bundle with EGDT or usual care that did not incorporate continuous monitoring of CVP and $\mathrm{ScvO}_{2}$. Patients in the EGDT group received significantly more fluids and were more likely to receive vasopressors, inotropes, and red cell transfusions than those in usual care. However, no significant difference in 90-day mortality was found. Compared with those receiving usual care, patients in the EGDT group had significantly higher organ failure scores at 6 hours and longer stays in the ICU and were more likely to require advanced cardiovascular support. Investigators also showed that average costs in the EGDT group were higher than in usual care but this difference was not statistically significant.

The ProCESS, ARISE, and ProMISe trials reported control group mortality rates that were markedly lower compared with the original trial by Rivers and colleagues. This likely reflects gradual improvements in intensive care since the 1990s, including the adoption of SSC guidelines that support early identification of sepsis and prompt initiation of antibiotics [53]. Indeed, patients assigned to usual care received fluid boluses within the first 6 hours and antibiotics prior to randomization. Titrating fluids to CVP and $\mathrm{ScvO}_{2}$, however, did not confer survival benefit to most patients. It remained unclear whether a subset of patients who fail to respond to initial resuscitation may benefit from such measures. The recent trials of EGDT also did not address whether monitoring CVP and $\mathrm{ScvO}_{2}$ is beneficial during the initiation of mechanical ventilation in patients with septic shock, when the risk of acute cardiovascular collapse is increased.

\section{Goals of early goal-directed therapy: mean arterial pressure}

In patients with hypotension despite adequate fluid repletion (defined as CVP of at least 8 to $12 \mathrm{~mm} \mathrm{Hg}$ ) or evidence of cardiogenic pulmonary edema, the SSC recommends the use of vasopressors to maintain blood pressure. The benefit of vasopressors in patients with refractory septic shock is well supported by evidence from randomized controlled trials [54]. The SSC currently advocates an MAP goal of $65 \mathrm{~mm} \mathrm{Hg}$ during the first 6 hours of treatment. Owing to the theoretical risk of coronary ischemia and acute renal and hepatic failure, higher blood pressure goals are not advised, except for patients with atherosclerosis or chronic hypertension [55]. This recommendation is based on evidence from observational studies and one small randomized trial by Bourgoin and colleagues [56-60], which showed no differences in tissue oxygenation or mortality for patients who received higher versus lower MAP targets.

In 2014, a randomized controlled trial called Sepsis and Mean Arterial Pressure (SEPSISPAM) was conducted at 29 centers in France to re-examine high versus low MAP goals in patients with septic shock [61]. The trial also sought to determine whether a subgroup of patients with chronic hypertension benefited from treatment with an MAP target of 80 to $85 \mathrm{~mm} \mathrm{Hg}$. Investigators found no significant difference in mortality between those treated with a low versus high MAP target. They also found that the incidence of atrial fibrillation was significantly increased among those in the high-target group compared with the low-target group $(6.7 \%$ versus $2.8 \%, P=0.02)$. Investigators showed that chronic hypertension patients who were treated with a higher MAP target were significantly less likely to require renal replacement therapy but did not have increased survival compared with the low-target group. These findings support an MAP goal of $65 \mathrm{~mm} \mathrm{Hg}$ in most patients with septic shock and suggest that a higher MAP goal may decrease morbidity among those with chronic hypertension.

The optimal timing of vasopressors relative to fluid infusion remains more controversial. Recently, a large 
multi-center observational study was undertaken in Canada, the United States, and Saudi Arabia to address this question [62]. In a retrospective analysis of 2,849 patients with septic shock, investigators found that mortality was lowest when vasopressors were delayed by 1 hour and infused from hours 1 to 6 following onset of shock. These findings are consistent with those of other retrospective cohort studies that support the early initiation of vasopressors $[63,64]$. This approach may decrease the volume of fluids necessary to maintain blood pressure. Indeed, patients in the recent ProCESS, ARISE, and ProMISe trials were more likely to receive vasopressors and required less fluids than patients in the original study by Rivers and colleagues (Table 2). Still, prospective randomized trials are needed to elucidate the optimal timing of vasopressors and volume of fluids during initial resuscitation.

\section{Goals of early goal-directed therapy: hemoglobin concentration}

In the original trial by Rivers and colleagues, packed red blood cell transfusions were used as part of the EGDT protocol and subsequently became one of the key components of sepsis care bundles advocated by the SSC. The SSC recommends using blood transfusions during the first 6 hours of septic shock, but guidelines for when to initiate therapy remain ambiguous and suggest that most patients are eligible for a liberal transfusion threshold. Goals of transfusion include a hematocrit of at least $30 \%$ or a hemoglobin concentration of between 7.0 and $9.0 \mathrm{~g} / \mathrm{dl}$. This recommendation is based on evidence from the Transfusion Requirements in Critical Care (TRICC) trial conducted in 1999 [65]. The TRICC trial was a randomized study that enrolled 838 critically ill patients, among whom only $16.7 \%$ had septic shock. Investigators showed that a liberal transfusion threshold of 10.0 to $12.0 \mathrm{~g} / \mathrm{dl}$ did not significantly improve mortality compared with a conservative threshold of 7.0 to $9.0 \mathrm{~g} / \mathrm{dl}$.

Recently, the Transfusion Requirements in Septic Shock (TRISS) trial re-examined transfusion thresholds in patients with sepsis [66]. This randomized study enrolled 998 patients from 32 ICUs in Scandinavia and showed that a hemoglobin threshold for transfusion of $7.0 \mathrm{~g} / \mathrm{dl}$ resulted in similar rates of mortality, ischemic events, and use of life support in comparison with a threshold of $9.0 \mathrm{~g} / \mathrm{dl}$. The conservative approach also decreased the use of blood products by $50 \%$. In the ProCESS, ARISE, and ProMISe trials, patients receiving EGDT were transfused according to goals described in the original trial by Rivers and colleagues: a target hematocrit of at least $30 \%$ if $\mathrm{ScvO}_{2}$ remained below 70 $\%$ despite appropriate fluid resuscitation. As a result, patients receiving EGDT were about twice as likely to receive transfusions in comparison with those receiving usual care but this did not improve mortality. These studies collectively suggest that a conservative transfusion threshold of $7.0 \mathrm{~g} / \mathrm{dl}$ is safe for the majority of patients with septic shock.

\section{Alternatives to central venous pressure and central venous oxygen saturation}

One of the key challenges of treating shock is the measurement of intravascular volume and oxygen delivery during fluid bolus therapy. This is of particular importance in patients with sepsis, who are at high risk of fluid overload. Previous studies have estimated that only $50 \%$ of hemodynamically unstable patients are fluid-responsive, highlighting the need for accurate measurement of volume status [67, 68]. Physical examination and chest radiography are simple methods of assessing volume but are statistically insensitive and unreliable. Static measurements of CVP and pulmonary capillary wedge pressure can be used but also have low sensitivity and specificity for predicting fluid responsiveness $[11,69]$. This is likely due to the nonlinear relationship between volume and pressure, which results from variable compliance of the cardiovascular system. The use of $\mathrm{ScvO}_{2}$ as an indirect marker of cardiac output and tissue oxygenation is also controversial. Previous studies have shown that $\mathrm{ScvO}_{2}$ does not always approximate mixed venous oxygen saturation $\left(\mathrm{SvO}_{2}\right)$, a more accurate marker of total body oxygen consumption [70].

This has prompted the development of alternative methods of monitoring fluid responsiveness in the ICU. Dynamic indices such as variation in stroke volume, pulse pressure, and the diameter of inferior vena cava (IVC) offer the advantage of real-time assessment of hemodynamic status. However, measurement of stroke volume and pulse pressure variation is typically reserved for patients who are receiving mechanical ventilation $[71,72]$. The IVC diameter can be measured in spontaneously breathing patients by ultrasound but provides only an indirect assessment of CVP [73]. Other techniques such as the passive leg-raise maneuver and minifluid challenge have thus been proposed [74, 75]. The mini-fluid challenge requires a bolus of 100 to $500 \mathrm{ml}$ of crystalloids infused over 10 to 30 minutes, whereas the passive leg-raise acts as a 'self' fluid challenge that increases cardiac preload. In these techniques, an ultrasound cardiac output monitor is used to estimate a patient's fluid responsiveness from position on the FrankStarling curve. A patient is considered fluid-responsive if cardiac output increases by at least $10 \%$ to $15 \%$ after the fluid challenge (Fig. 3).

Several ongoing trials are investigating the potential role of real-time monitoring of cardiac output to guide fluid resuscitation in sepsis. A Goal-Oriented Non-Invasive Sepsis Trial (AGONIST) is a randomized study in Singapore that 


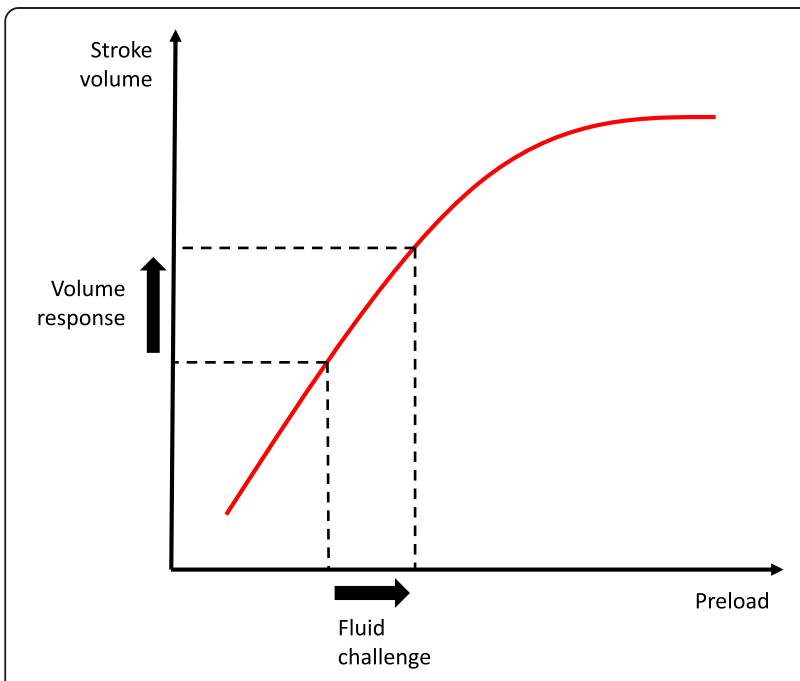

Fig. 3 Measuring fluid responsiveness by cardiac ultrasound. A patient is considered fluid-responsive if left ventricular function falls along the ascending portion of the Frank-Starling curve. Additional fluids given above this zone do not increase cardiac output and worsen the risk of volume overload. Measurement of stroke volume and cardiac output by Doppler ultrasound may allow more accurate estimation of fluid responsiveness in patients receiving intravenous fluid therapy

will investigate the passive leg-raise maneuver and ultrasound cardiac output monitor for patients with sepsis. The Bioimpedance Analysis in Septic Intensive Care Unit Patients (BIOVISION) is testing another noninvasive method of volume assessment. Bioimpedance analysis has been used for several decades to measure volume status and guide fluid management in patients receiving hemodialysis [76]. In this technique, a small alternating current is passed between electrodes on the hand and foot. The measured drop in voltage reflects resistance to electrical flow or 'impedance', which is inversely proportional to total body water.

The role of microcirculation in shock and resuscitation is another potential area of future research. Tissue perfusion and oxygenation are commonly assessed via measurements of arterial lactate concentration. However, previous randomized trials of lactate-guided resuscitation have offered conflicting evidence of survival benefit, and the SSC does not currently advocate a specific goal for lactate reduction during initial treatment of septic shock [77, 78]. Direct observation of microcirculation may offer more accurate assessments of vital organ blood flow and oxygenation [79, 80]. Unfortunately, measurement of microvascular flow is limited to easily accessible organs such as the skin and tongue, and there is considerable inter-operator variation with currently available techniques.

\section{Emerging paradigms in sepsis trials}

In a subset analysis of the ARISE trial, investigators showed that EGDT did not improve mortality in patients with increased severity of illness [50]. The quantification of disease severity in critically ill patients, however, remains a significant challenge in clinical trials and may confound comparative analyses of treatment effect. Scoring systems such as the Acute Physiology and Chronic Health Evaluation are commonly used but were not originally designed for stratifying patients in clinical trials and have been validated in only the first 24 to 48 hours of hospital admission. These population-based statistical models predict ICU mortality but do not accurately reflect pathology in individual patients [81]. Disease severity would likely be better characterized by using molecular diagnostics. Unfortunately, whereas dozens of sepsis biomarkers have been proposed, none has demonstrated sufficient specificity and sensitivity for clinical use [82]. Recent studies suggest that gene expression profiling might offer an alternative approach to stratifying patients in clinical trials [83].

Another barrier to evidence-based sepsis care arises from limitations inherent in traditional randomized controlled trials, which are ill equipped for answering clinical questions in patients with evolving disease states and myriad treatment interventions. Dynamic 'adaptive' trial designs have recently emerged as an alternative for studies in critical care. As data accumulate in an adaptive trial, the allocation ratio is changed to favor the treatment group that appears superior. This approach allows investigators to achieve statistical significance with smaller samples and test multiple treatment options that are modifiable as disease severity changes among participants [84]. Adaptive clinical trials have been used previously in many oncology studies and may offer greater safety and efficiency than classic randomized trials [85].

\section{Conclusions}

Conventional management that focuses on early antibiotics and targeted resuscitation has contributed to improvements in survival of patients with septic shock over the last decade. New evidence from the ProCESS, ARISE and PRoMISe trials, however, suggests that structured 'early goal-directed resuscitation' with routine placement of a central venous catheter, monitoring of mixed venous oxygen saturation and aggressive red cell transfusion does not improve outcomes in most patients with septic shock. The nuances of fluid and vasopressor administration in early septic shock remain incompletely defined. Further, development and validation of practical methods for accurately assessing optimal fluid administration is needed. Future studies that seek to address these issues will likely benefit from emerging novel techniques, including molecular diagnostics and adaptive trial designs. 


\section{Abbreviations}

ARISE: Australasian Resuscitation in Sepsis Evaluation; CVP: Central venous pressure; EGDT: Early goal-directed therapy; ICU: Intensive care unit; IVC: Inferior vena cava; MAP: Mean arterial pressure; ProCESS: Protocolized Care for Early Septic Shock; ProMISe: Protocolised Management of Sepsis; $\mathrm{ScrO}_{2}$ : Central venous oxygen saturation; SSC: Surviving Sepsis Campaign; TRICC: Transfusion Requirements in Critical Care.

\section{Competing interests}

The authors declare that they have no competing interests.

\section{Acknowledgments}

The authors would like to acknowledge and thank Derek C. Angus for his review of the manuscript and helpful discussions.

\section{Author details}

'Division of Pulmonary Disease and Critical Care Medicine, Department of Internal Medicine, Virginia Commonwealth University School of Medicine, P.O. Box 980050, Richmond, VA 23298, USA. ²Division of General Internal Medicine, Department of Internal Medicine, Virginia Commonwealth University School of Medicine, P.O. Box 980070, Richmond, VA 23298, USA. ${ }^{3}$ Division of Infectious Diseases, Department of Internal Medicine, Virginia Commonwealth University School of Medicine, P.O. Box 980019, Richmond, VA 23298, USA.

\section{Published online: 28 August 2015}

\section{References}

1. Angus DC, van der Poll T. Severe sepsis and septic shock. N Engl J Med. 2013;369:840-51.

2. Hall MJ, Williams SN, DeFrances CJ, Golosinskiy A. Inpatient care for septicemia or sepsis: a challenge for patients and hospitals. NCHS Data Brief. 2011;62:1-8.

3. Martin GS, Mannino DM, Eaton S, Moss M. The epidemiology of sepsis in the United States from 1979 through 2000. N Engl J Med. 2003:348:1546-54.

4. Angus DC, Linde-Zwirble WT, Lidicker J, Clermont G, Carcillo J, Pinsky MR. Epidemiology of severe sepsis in the United States: analysis of incidence, outcome, and associated costs of care. Crit Care Med. 2001;29:1303-10.

5. Danai P, Martin GS. Epidemiology of sepsis: recent advances. Curr Infect Dis Rep. 2005;7:329-34.

6. Winters BD, Eberlein M, Leung J, Needham DM, Pronovost PJ, Sevransky JE. Long-term mortality and quality of life in sepsis: a systematic review. Crit Care Med. 2010;38:1276-83.

7. Rivers E, Nguyen B, Havstad S, Ressler J, Muzzin A, Knoblich B, et al. Early goal-directed therapy in the treatment of severe sepsis and septic shock. N Engl J Med. 2001;345:1368-77.

8. Dellinger RP, Levy MM, Rhodes A, Annane D, Gerlach H, Opal SM, et al. Surviving sepsis campaign: international guidelines for management of severe sepsis and septic shock: 2012. Crit Care Med. 2013;41:580-637.

9. Marik PE. Early management of severe sepsis: concepts and controversies. Chest. 2014;145:1407-18

10. Vazquez-Guillamet C, Scolari M, Zilberberg MD, Shorr AF, Micek ST, Kollef M. Using the number needed to treat to assess appropriate antimicrobial therapy as a determinant of outcome in severe sepsis and septic shock. Crit Care Med. 2014:42:2342-9.

11. Marik PE, Baram M, Vahid B. Does central venous pressure predict fluid responsiveness? A systematic review of the literature and the tale of seven mares. Chest. 2008;134:172-8.

12. McGee DC, Gould MK. Preventing complications of central venous catheterization. N Engl J Med. 2003;348:1123.

13. Levy MM, Fink MP, Marshall JC, Abraham E, Angus D, Cook D, et al. 2001 SCCM/ESICM/ACCP/ATS/SIS International Sepsis Definitions Conference. Crit Care Med. 2003;31:1250-6.

14. King EG, Bauzá GJ, Mella JR, Remick DG. Pathophysiologic mechanisms in septic shock. Lab Invest. 2014;94:4-12.

15. Vincent $J$, Zhang $H$, Szabo C, Preiser JC. Effects of nitric oxide in septic shock. Am J Respir Crit Care Med. 2000;161:1781-5.

16. Kirkeboen KA, Strand OA. The role of nitric oxide in sepsis - an overview. Acta Anaesthesiol Scand. 1999;43:275-88.
17. Zanotti-Cavazzoni SL, Hollenberg SM. Cardiac dysfunction in severe sepsis and septic shock. Curr Opin Crit Care. 2009;15:392-7.

18. Astiz ME, DeGent GE, Lin RY, Rackow EC. Microvascular function and rheologic changes in hyperdynamic sepsis. Crit Care Med. 1995;23:265-71.

19. Lush CW, Kvietys PR. Microvascular dysfunction in sepsis. Microcirculation. 2000:7:83-101.

20. De Backer D, Creteur J, Preiser JC, Dubois MJ, Vincent JL. Microvascular blood flow is altered in patients with sepsis. Am J Respir Crit Care Med. 2002;166:98-104.

21. Glassford NJ, Eastwood GM, Bellomo R. Physiological changes after fluid bolus therapy in sepsis: a systematic review of the contemporary literature. Crit Care. 2014;18 Suppl 2:34.

22. Kumar A, Roberts D, Wood KE, Light B, Parrillo JE, Sharma S, et al. Duration of hypotension prior to initiation of effective antimicrobial therapy is the critical determinant of survival in human septic shock. Crit Care Med. 2006;34:1589-96

23. Gaieski DF, Mikkelsen ME, Band RA, Pines JM, Massone R, Furia FF, et al. Impact of time to antibiotics on survival in patients with severe sepsis or septic shock in whom early goal-directed therapy was initiated in the emergency department. Crit Care Med. 2010;38:1045-53.

24. Daniels R. Surviving the first hours in sepsis: getting the basics right (an intensivist's perspective). J Antimicrob Chemother. 2011;66 Suppl 2:11-23.

25. Gao F, Melody T, Daniels DF, Giles S, Fox S. The impact of compliance with 6-hour and 24-hour sepsis bundles on hospital mortality in patients with severe sepsis: a prospective observational study. Crit Care. 2005;9:R764-70.

26. Sebat F, Johnson D, Musthafa AA, Watnik M, Moore S, Henry K, et al. A multidisciplinary community hospital program for early and rapid resuscitation of shock in nontrauma patients. Chest. 2005;127:1729-43.

27. Micek ST, Roubinian N, Heuring T, Bode M, Williams J, Harrison C, et al. Before-after study of a standardized hospital order set for the management of septic shock. Crit Care Med. 2006:34:2707-13.

28. Kortgen A, Niederprum P, Bauer M. Implementation of an evidence-based 'standard operating procedure' and outcome in septic shock. Crit Care Med. 2006:34:943-9.

29. Shapiro NI, Howell MD, Talmor D, Lahey D, Ngo L, Buras J, et al. Implementation and outcomes of the Multiple Urgent Sepsis Therapies (MUST) protocol. Crit Care Med. 2006;34:1025-32.

30. Trzeciak S, Dellinger RP, Abate NL, Cowan RM, Stauss M, Kilgannon JH, et al. Translating research to clinical practice: a 1-year experience with implementing early goal-directed therapy for septic shock in the emergency department. Chest. 2006;129:225-32.

31. Nguyen HB, Corbett SW, Steele R, Banta J, Clark RT, Hayes SR, et al. Implementation of a bundle of quality indicators for the early management of severe sepsis and septic shock is associated with decreased mortality. Crit Care Med. 2007;35:1105-112.

32. Jones AE, Focht A, Horton JM, Kline JA. Prospective external validation of the clinical effectiveness of an emergency department-based early goal-directed therapy protocol for severe sepsis and septic shock. Chest. 2007;132:425-32.

33. Ferrer R, Artigas A, Levy MM, Blanco J, González-Díaz G, Garnacho-Montero $J$, et al. Improvement in process of care and outcome after a multicenter severe sepsis educational program in Spain. JAMA. 2008;299:2294-303.

34. Puskarich MA, Marchick MR, Kline JA, Steuerwald MT, Jones AE. One year mortality of patients treated with an emergency department based early goal directed therapy protocol for severe sepsis and septic shock: a before and after study. Crit Care. 2009;13:R167.

35. Girardis M, Rinaldi L, Donno L, Marietta M, Codeluppi M, Marchegiano P, et al. Effects on management and outcome of severe sepsis and septic shock patients admitted to the intensive care unit after implementation of a sepsis program: a pilot study. Crit Care. 2009;13:R143.

36. Thiel SW, Asghar MF, Micek ST, Reichley RM, Doherty JA, Kollef MH. Hospital-wide impact of a standardized order set for the management of bacteremic severe sepsis. Crit Care Med. 2009;37:819-24.

37. Castellanos-Ortega A, Suberviola B, García-Astudillo LA, Holanda MS, Ortiz F, Llorca J, et al. Impact of the Surviving Sepsis Campaign protocols on hospital length of stay and mortality in septic shock patients: results of a three-year follow-up quasi-experimental study. Crit Care Med. 2010;38:1036-43.

38. Cardoso T, Carneiro AH, Ribeiro O, Teixeira-Pinto A, Costa-Pereira A. Reducing mortality in severe sepsis with the implementation of a core 
6-hour bundle: results from the Portuguese community-acquired sepsis study (SACiUCI study). Crit Care. 2010;14:R83.

39. Nguyen HB, Kuan WS, Batech M, Shrikhande P, Mahadevan M, Li CH, et al. Outcome effectiveness of the severe sepsis resuscitation bundle with addition of lactate clearance as a bundle item: a multi-national evaluation. Crit Care. 2011;15:R229.

40. Westphal GA, Koenig Á, Caldeira Filho M, Feijó J, de Oliveira LT, Nunes F, et al. Reduced mortality after the implementation of a protocol for the early detection of severe sepsis. J Crit Care. 2011;26:76-81.

41. Castellanos-Ortega A, Suberviola B, Garcia-Astudillo LA, Ortiz F, Llorca J, Delgado-Rodriguez M. Late compliance with the sepsis resuscitation bundle: impact on mortality. Shock. 2011;36:542-7.

42. Shiramizo SC, Marra AR, Durao MS, Paes AT, Edmond MB, dos Santos OF. Decreasing mortality in severe sepsis and septic shock patients by implementing a sepsis bundle in a hospital setting. PLoS. 2011;6:e26790.

43. Sivayoham N, Rhodes A, Jaiganesh T, van Zyl SN, Elkhodhair S, Krishnanandan S. Outcomes from implementing early goal-directed therapy for severe sepsis and septic shock: a 4-year observational cohort study. Eur J Emerg Med. 2012;19:235-40.

44. Jeon K, Shin TG, Sim MS, Suh GY, Lim SY, Song HG, et al. Improvements in compliance with resuscitation bundles and achievement of end points after an educational program on the management of severe sepsis and septic shock. Shock. 2012;37:463-7.

45. Miller 3rd RR, Dong L, Nelson NC, Brown SM, Kuttler KG, Probst DR, et al. Multicenter implementation of a severe sepsis and septic shock treatment bundle. Am J Respir Crit Care Med. 2013;188:77-82.

46. Levy MM, Rhodes A, Phillips GS, Townsend SR, Schorr CA, Beale R, et al. Surviving Sepsis Campaign: association between performance metrics and outcomes in a 7.5-year study. Crit Care Med. 2014;40:1623-33.

47. Gluud LL. Bias in clinical intervention research. Am J Epidemiol. 2006;163:493-501.

48. ProCESS/ARISE/ProMISe Methodology Writing Committee, Huang DT, Angus DC, Barnato A, Gunn SR, Kellum JA, et al. Harmonizing international trials of early goal-directed resuscitation for severe sepsis and septic shock: methodology of ProCESS, ARISE, and ProMISe. Intensive Care Med. 2013;39:1760-75.

49. ProCESS Investigators, Yealy DM, Kellum JA, Huang DT, Barnato AE, Weissfeld $L A$, et al. A randomized trial of protocol-based care for early septic shock. N Engl J Med. 2014;370:1683-93.

50. ARISE Investigators; ANZICS Clinical Trials Group, Peake SL, Delaney A, Bailey M, Bellomo R, Cameron PA, et al. Goal-directed resuscitation for patients with early septic shock. N Engl J Med. 2014;371:1496-506.

51. Reade MC, Huang DT, Bell D, Coats TJ, Cross AM, Peake SL, et al. Severe sepsis: international and specialty variations in initial management. Crit Care. 2008;12 Suppl 2:415.

52. Mouncey PR, Osborn TM, Power GS, Harrison DA, Sadique MZ, Grieve RD, et al. Trial of early, goal-directed resuscitation for septic shock. N Engl J Med. 2015;372:1301-11.

53. Stevenson EK, Rubenstein AR, Radin GT, Wiener RS, Walkey AJ. Two decades of mortality trends among patients with severe sepsis: a comparative meta-analysis. Crit Care Med. 2014;42:625-31.

54. Russell JA, Walley KR, Singer J, Gordon AC, Hébert PC, Cooper DJ, et al. Vasopressin versus norepinephrine infusion in patients with septic shock N Engl J Med. 2008;358:877-87.

55. Leone M, Asfar P, Radermacher P, Vincent $J$, Martin C. Optimizing mean arterial pressure in septic shock: a critical reappraisal of the literature. Crit Care. 2015;19:101.

56. Ledoux D, Astiz ME, Carpati CM, Rackow EC. Effects of perfusion pressure on tissue perfusion in septic shock. Crit Care Med. 2000;28:2729-32.

57. Bourgoin A, Leone M, Delmas A, Garnier F, Albanese J, Martin C. Increasing mean arterial pressure in patients with septic shock: effects of oxygen variables and renal function. Crit Care Med. 2005;33:780-6.

58. Jhanji S, Stirling S, Patel N, Hinds CJ, Pearse RM. The effect of increasing doses of norepinephrine on tissue oxygenation and microvascular flow in patients with septic shock. Crit Care Med. 2009;37:1961-6.

59. Thooft A, Favory R, Salgado DR, Taccone FS, Donadello K, De Backer D, et al. Effects of changes in arterial pressure on organ perfusion during septic shock. Crit Care. 2011;15:R222.

60. Badin J, Boulain T, Ehrmann S, Skarzynski M, Bretagnol A, Buret J, et al. Relation between mean arterial pressure and renal function in the early phase of shock: a prospective, explorative cohort study. Crit Care. 2011;15:R135.

61. Asfar P, Meziani F, Hamel JF, Grelon F, Megarbane B, Anguel N, et al. High versus low blood-pressure target in patients with septic shock. N Engl J Med. 2014;370:1583-93.

62. Waechter J, Kumar A, Lapinsky SE, Marshall J, Dodek P, Arabi Y, et al. Interaction between fluids and vasoactive agents on mortality in septic shock: a multicenter, observational study. Crit Care Med. 2014;42:2158-68.

63. Bai X, Yu W, Ji W, Lin Z, Tan S, Duan K, et al. Early versus delayed administration of norepinephrine in patients with septic shock. Crit Care. 2014;18:532.

64. Beck V, Chateau D, Bryson GL, Pisipati A, Zanotti S, Parrillo JE, et al. Timing of vasopressor initiation and mortality in septic shock: a cohort study. Crit Care. 2014;18:R97.

65. Hébert PC, Wells G, Blajchman MA, Marshall J, Martin C, Pagliarello G, et al. A multicenter, randomized, controlled clinical trial of transfusion requirements in critical care. Transfusion Requirements in Critical Care Investigators, Canadian Critical Care Trials Group. N Engl J Med. 1999;340:409-17.

66. Holst LB, Haase N, Wetterslev J, Wernerman J, Guttormsen AB, Karlsson S, et al. Lower versus higher hemoglobin threshold for transfusion in septic shock. N Engl J Med. 2014;371:1381-91.

67. Monnet X, Teboul J-L. Volume responsiveness. Curr Opin Crit Care. 2007;13:549-53.

68. Marik PE, Monnet X, Teboul J-L. Hemodynamic parameters to guide fluid therapy. Annals of Intensive Care. 2011;1:1.

69. Kalantari K, Chang JN, Ronco C, Rosner MH. Assessment of intravascular volume status and volume responsiveness in critically ill patients. Kidney Int. 2013;83:1017-28.

70. Walley KR. Use of central venous oxygen saturation to guide therapy. Am J Respir Crit Care Med. 2011;184:514-20.

71. Monnet X, Teboul J-L. Assessment of volume responsiveness during mechanical ventilation: recent advances. Crit Care. 2013;17:217.

72. Marik PE, Cavallazzi R, Vasu T, Hirani A. Dynamic changes in arterial waveform derived variables and fluid responsiveness in mechanically ventilated patients: a systematic review of the literature. Crit Care Med. 2009;37:2642-7.

73. Nagdev AD, Merchant RC, Tirado-Gonzalez A, Sisson CA, Murphy MC Emergency department bedside ultrasonographic measurement of the caval index for noninvasive determination of low central venous pressure. Ann Emerg Med. 2010;55:290-5.

74. Muller L, Toumi M, Bousquet PJ, Riu-Poulenc B, Louart G, Candela D, et al. An increase in aortic blood flow after an infusion of $100 \mathrm{ml}$ colloid over 1 minute can predict fluid responsiveness: the mini-fluid challenge study. Anesthesiology. 2011;115:541-7.

75. Duus N, Shogilev DJ, Skibsted S, Zijlstra HW, Fish E, Oren-Grinberg A, et al. The reliability and validity of passive leg raise and fluid bolus to assess fluid responsiveness in spontaneously breathing emergency department patients. J Crit Care. 2015;30(217):e1-5.

76. Davies SJ, Davenport A. The role of bioimpedance and biomarkers in helping to aid clinical decision-making of volume assessments in dialysis patients. Kidney Int. 2014;86:489-96.

77. Jansen TC, van Bommel J, Schoonderbeek FJ, Sleeswijk Visser SJ, van der Klooster JM, Lima AP, et al. Early lactate-guided therapy in intensive care unit patients: a multicenter, open-label randomized controlled trial. Am J Respir Crit Care Med. 2010;182:752-61.

78. Jones AE, Shapiro NI, Trzeciak S, Arnold RC, Claremont HA, Kline JA, et al. Lactate clearance vs central venous oxygen saturation as goals of early sepsis therapy: a randomized clinical trial. JAMA. 2010;303:739-46.

79. Ait-Oufella H, Bourcier S, Alves M, Galbois A, Baudel JL, Margetis D, et al. Alteration of skin perfusion in mottling area during septic shock. Ann Intensive Care. 2013;3:31.

80. Sakr Y, Dubois MJ, De Backer D, Creteur J, Vincent JL. Persistent microcirculatory alterations are associated with organ failure and death in patients with septic shock. Crit Care Med. 2004;32:1825-31.

81. Vincent JL, Opal SM, Marshall JC. Ten reasons why we should not use severity scores as entry criteria for clinical trials or in our treatment decisions. Crit Care Med. 2010:38:283-7.

82. Pierrakos C, Vincet JL. Sepsis biomarkers: a review. Crit Care. 2010;14:R15. 
83. Maslove DM, Tang BM, McLean AS. Identification of sepsis subtypes in critically ill adults using gene expression profiling. Crit Care. 2012;16:R183.

84. Kairalla JA, Coffey CS, Thomann MA, Muller KE. Adaptive trial designs: a review of barriers and opportunities. Trials. 2012;13:145.

85. Berry DA. Adaptive clinical trials in oncology. Nat Rev Clin Oncol. 2011;9:199-207. 